\title{
Frequency based detection and monitoring of small scale explosive activity by comparing satellite and ground based infrared observations at Stromboli Volcano, Italy
}

\author{
Anna Worden ${ }^{\mathrm{a}, *}$, Jonathan Dehn ${ }^{\mathrm{a}}$, Maurizio Ripepe ${ }^{\mathrm{b}}$, Dario Delle Donne ${ }^{\mathrm{b}}$ \\ a Geophysical Institute, University of Alaska Fairbanks, 903 Koyukuk Drive, Fairbanks, AK 99775, United States \\ b Dipartimento di Scienze della Terra, Università di Firenze, via La Pira 4, 50121 Florence, Italy
}

\section{A R T I C L E I N F O}

\section{Article history:}

Received 13 February 2014

Accepted 15 July 2014

Available online 23 July 2014

\section{Keywords:}

Remote sensing

Stromboli Volcano

Thermal infrared

Explosive activity

\begin{abstract}
A B S T R A C T
Thermal activity is a common precursor to explosive volcanic activity. The ability to use these thermal precursors to monitor the volcano and obtain early warning about upcoming activity is beneficial for both human safety and infrastructure security. By using a very reliably active volcano, Stromboli Volcano in Italy, a method has been developed and tested to look at changes in the frequency of small scale explosive activity and how this activity changes prior to larger, ash producing explosive events. Thermal camera footage was used to designate parameters for typical explosions at Stromboli (size of spatter field, cooling rate, frequency of explosions) and this information was applied to characterize explosions in satellite imagery. Satellite data from The National Aeronautics and Space Administration's Moderate Resolution Imaging Spectroradiometer (MODIS) and US/Japan designed Advanced Spaceborne Thermal Emission and Reflection Radiometer (ASTER) for numerous periods in 2002 to 2009 were analyzed for thermal features which were used to calculate an estimate of the level of activity during the given time period. The results at Stromboli showed a high level of small scale explosions which stop completely prior to large paroxysmal eruptive episodes. This activity also corresponds well to seismic and infrasonic records at Stromboli, indicating that this thermal infrared monitoring method may be used in conjunction with other detection methods where available, and also indicates that it may be a useful method for volcano monitoring when other methods (e.g. seismic instrumentation, infrasound arrays, etc.) are not available.
\end{abstract}

(c) 2014 Elsevier B.V. All rights reserved.

\section{Introduction}

Satellite remote sensing has proved to be a useful tool in the monitoring of volcanoes (Dehn et al., 2000; Harris et al., 2000; Dean et al., 2002; Webley et al., 2009; Dehn and Harris, in press). This tool becomes especially useful at remote volcanoes where field work is not always feasible or ground observations are not available. Satellite sensors collect data that cover larger areas more frequently than is possible for researchers in the field. This data can be analyzed to monitor activity at volcanoes all over the world, regardless of location, activity, and instrumentation logistics.

In order to use the remote sensing capabilities to their fullest, it is important to develop a method using data/images from a variety of satellite sensors to determine the type and frequency of activity occurring on the ground. Some eruptions types show recognizable signals in thermal satellite data, i.e. strombolian eruptions show intermittent hot features, whereas lava flows are more persistent (Dehn et al., 2000; Dehn and Harris, in press). For strombolian eruptions, each

\footnotetext{
* Corresponding author at: Geophysical Institute, University of Alaska Fairbanks, 903 Koyukuk Drive, Fairbanks, AK 99775-7320, United States. Tel.: + 19079788932.

E-mail address: akworden@gi.alaska.edu (A. Worden).
}

thermal signal represents a discrete explosion, but due to the timing of the satellite overpass and conditions at the volcano, some events may be missed. By linking verifiable ground observations to a robust satellite data set, statistics can be applied to show about how many events occurred, and more importantly if the activity is increasing or decreasing. In developing this method, the use of a well studied, monitored, and frequently erupting volcano was essential. For this reason, Stromboli Volcano in Italy was chosen as our 'test-case'. In addition, beginning with a well known and monitored volcano allows for identification of factors that could have a large impact at noninstrumented volcanoes. It is important to have a continuous data set, a known record of eruptive history, good temporal resolution, and appropriate spatial resolutions to get the optimal results with the best data set. A continuous baseline is also very important when considering the detection of changes in eruptive character and frequency. For most volcanoes, there are archives of satellite data available for use in the creation of such baselines; such as at the Alaska Volcano Observatory (AVO) Remote Sensing (RS) (Dean et al., 2002), National Oceanic and Atmospheric Administration (NOAA) CLASS website (2013), National Aeronautical and Space Administration (NASA) Moderate Resolution Imaging Spectroradiometer (MODIS) Rapid Response website (2013), MODVOLC System (Wright et al., 2004); it simply 
requires a consistent method for sorting through the data, analyzing the activity and statistically comparing them. The aim is to better monitor the volcanoes, improve our understanding of the volcanic processes, and making use of any data made available.

\subsection{Background}

Stromboli Volcano is located in the Aegean Sea, North of Sicily (Fig. 1). This island has been referred to as the "Lighthouse of the Mediterranean" due to its regular and spectacular eruptive activity over the past 2000-2500 years (Judd, 1881; Rosi et al., 2000). A period of nearly continuous eruptive activity began in 1934 (Barberi et al., 1993) and has only been interrupted for short periods of time, usually associated with a slight change in eruptive behavior (Bertagnini et al., 2011).

The volcanism in the Tyrrhenian region has resulted from a complex series of subduction, rifting, basin formation, and extension (Ferrari and Manetti, 1993). Stromboli is the northernmost island in the Aeolian Arc, a portion of the larger Calabrian Arc, which is largely related to the subduction of the African Plate beneath the Eurasian Plate (Ferrari and Manetti, 1993). During the past 100,000 years the main eruptive centers on Stromboli have been focused in the central part of the cone at about 750-800 $\mathrm{m}$ above sea level (ASL) (Hornig-Kjarsgaard et al., 1993). The main cone is built up of calc-alkaline, potassic, and most recently, shoshonitic basalts (Francalanci, 1993).

The summit crater of Stromboli is composed of a dynamic complex of active and inactive vents (Chouet et al., 1974; GVN, 1988, 1990, 1991a, 1993, 1997, 2003). During the field work for this study (summer of 2010), there were a total of five vents, three of which were explosively active with the remaining two a fairly consistent source of gas puffing and emission (Fig. 1b). Two vents (North-East crater 1 [NE1] and North-East crater 2 [NE2]) were chosen for focus in this study due to their eruptive nature, frequently depositing spatter fields onto the inner and outer flanks of the volcano.

\subsection{Small scale explosive activity-strombolian explosions}

Small scale explosive activity is some of the most common volcanic activity on Earth, occurring at a large number of volcanoes around the world (e.g. Pacaya, Guatemala (GVN, 2007); Etna, Italy (Andronico et al., 2005); Paricutin, Mexico (Pioli et al., 2008); Villarrica and Llaima, Chile (Aguilera, 2005)). This type of activity occurs at shield, composite, and cinder cone volcanoes and can occur in conjunction with fissure eruptions, dome destroying explosions, and other types of activity. This activity can be part of a larger eruptive suite, but can also be an indication of a change in the activity of a volcanic center. For this latter reason, it is important to be able to monitor for the introduction or change in the character of small scale explosive activity, as these changes can lead to heightened levels of volcanism which can in turn threaten populations, communities, environments/habitats, and human infrastructure.

Small-scale explosive activity at Stromboli is characterized by transient explosions throwing molten material, as well as entrained edifice material, tens to hundreds of meters above the crater (Blackburn et al., 1976; Harris and Ripepe, 2007; Patrick et al., 2007). These explosions can also contain ash and volcanic gases. The ash portion of small explosions can be a product of fragmented juvenile material, but is more likely due to the mechanical erosion of edifice material or cooled crater infill from previous explosions. There are multiple possible mechanisms for small explosions. Some explosions are due to large gas slugs rising through a volcanic conduit and bursting at a free surface (dubbed strombolian explosions, due to the typical activity seen throughout history at Stromboli Volcano (Lacroix, 1904; Walker, 1973; Wohletz and Heiken, 1992). At other volcanoes, small explosions may be due to a buildup of pressure blowing a small plug or dome out of the vent (e.g. Cleveland, Alaska, D. Schneider, Pers. Comm., 2012; Redoubt, Alaska, S. Prejean, Pers. Comm., 2009; Galeras, Columbia, Stix et al., 1997; Soufrière Hills, Montserrat, Diller et al., 2006). There is also the possibility of a mixture of these two mechanisms, as each volcano has unique activity, crater geometry, magma plumbing system, and magma supply.

In the case of Stromboli Volcano, normal activity is similar to the description of strombolian activity above. However, violent strombolian activity and strombolian paroxysms are periods of activity including cessation of small explosions, lava flows, and much larger ash producing explosions (MacDonald, 1972; Barberi et al., 1993; Calvari et al., 2006; Rosi et al., 2006; Ripepe and Harris, 2008). The small explosions at

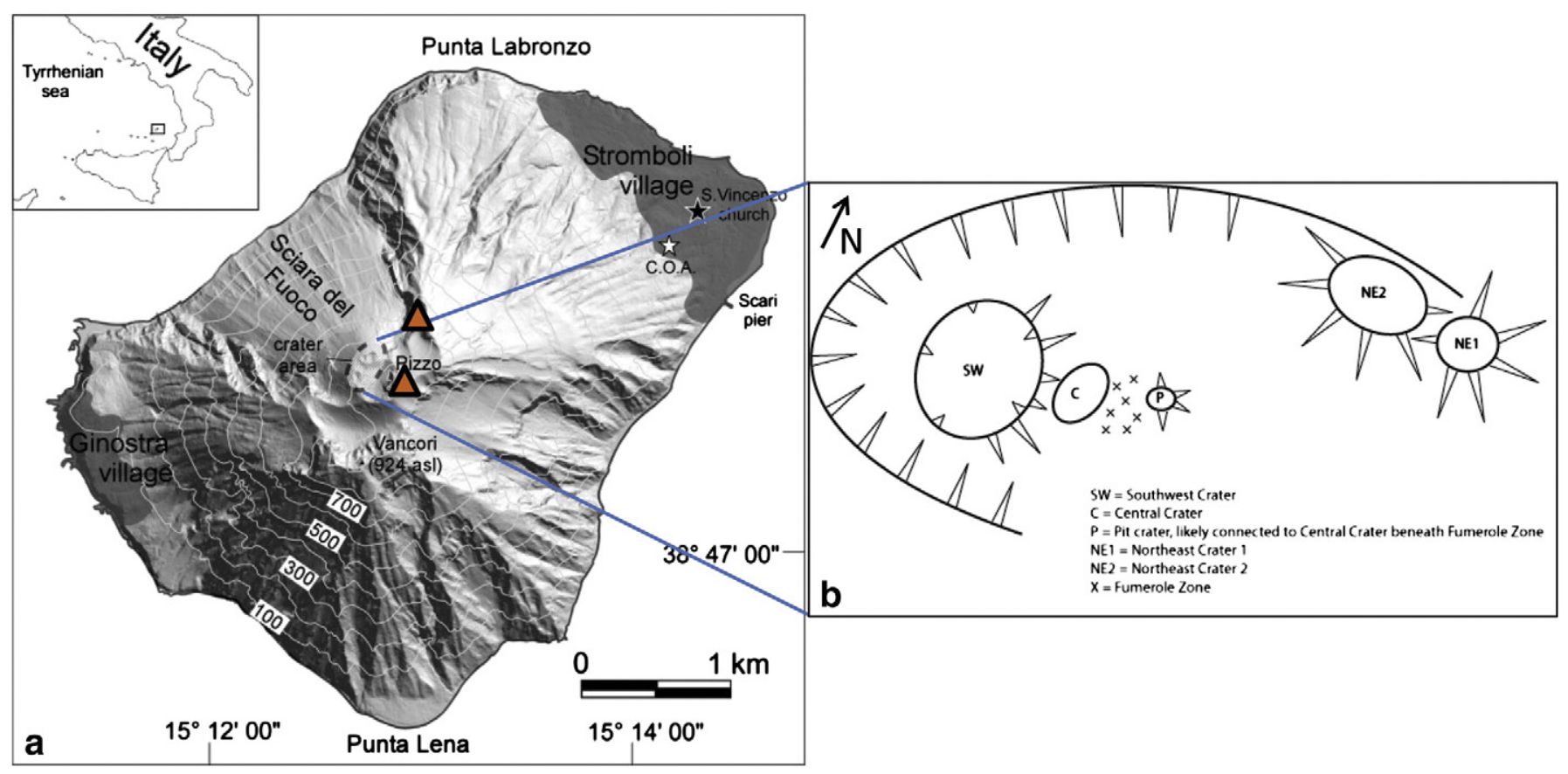

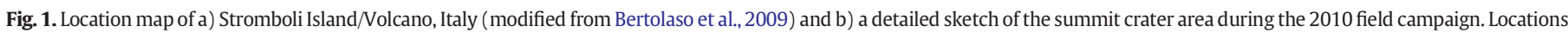
of thermal camera deployment are marked with triangles in (a). Both camera locations were chosen to view NE1 and NE2 and were 250-400 m from the vents. 
Stromboli have been broken into two classes by Patrick et al. (2007). Type 1 explosions are mainly made up of coarse ballistic particles. Type 2 explosions contain some portion of ash, Type $2 \mathrm{a}$ has ash and ballistic material, and Type $2 \mathrm{~b}$ has no ballistic material. These explosion types will be discussed in more detail in following sections.

\subsection{Source and transience of thermal anomalies}

\subsubsection{Thermal source}

Small scale explosions produce spatter fields of hot, semi-molten bombs and other tephra. These spatter fields are the main component of the thermal signal that can be seen from various satellite platforms and their associated sensors (Dehn et al., 2000). These signals are indicative of a very recent eruption due to the fast cooling rate of material once it is deposited post-eruption. A feature is considered a thermal anomaly if any area of pixels in an image appear to be significantly (or detectably) brighter (and therefore warmer) than the background (Dehn et al., 2000; Dean et al., 2002). When processing data, considerations are made for viewing angle, volcano geometry, and other factors (Dehn and Harris, in press). The visually detected anomalies indicate larger explosions that can change the temperature of a pixel enough for detection. Smaller explosions are much more common and much harder to detect, though not impossible.

Patrick et al. (2007) describe the types of explosions at Stromboli and characterize them as either Type 1 or Type 2 explosions depending on their character and deposits (Fig. 2). Type 1 explosions are dominated by coarse ballistic particles, incandescent material, and spatter with no associated ash emission. These explosions are likely the product of gas slug bursts at the surface of the magma column in an open vent scenario. Type 2 explosions are further broken into Type 2a, explosions with an optically thick ash plume in addition to ballistic particles, and Type $2 \mathrm{~b}$, explosions with an optically thick ash plume but no accompanying ballistic material. Both $2 \mathrm{a}$ and $2 \mathrm{~b}$ explosions are the result of the bursting gas slug at the surface of the magma column in a choked vent scenario. In these instances, cooled material has filled in the vent area and limits the power of the explosion. This infill will also be the source of the ash portion of the explosion, as the energy released breaks up the material and forces it out of the vent. Types 1 and 2a will produce a spatter field on the volcanoes flanks and may be detectable by satellite sensors, though in Type 2a explosions ash plumes may obscure a sensors' view of the spatter.

\subsubsection{Spatial distribution}

The size of a spatter field is a direct result of the size of the explosion, the existence or amount of pre-eruptive crater infill, crater geometry, and the type of material erupted. For a Type 1 explosion the spatter field will consist of large semi-molten blobs, hot rocks, and other coarse ballistic material and may be quite large, as all the explosive energy is used to deposit this material (Harris and Ripepe, 2007; Patrick et al., 2007; Harris et al., 2013; Fig. 2, Type 1). Type 2a explosion will likely form a small spatter field, but its size will depend on the amount of eruptive energy used to break through any crater infill. Type $2 \mathrm{~b}$ explosions, resulting from an explosion through a vent choked with infill, will not produce a spatter field at all, as the only material to leave the vent will be gas and ash (Patrick et al., 2007). In these cases, all of the spatter is either constrained beneath the crater infill, or the energy required to break up the crater infill causes too weak an explosion to significantly distribute any juvenile material (Fig. 2, Type 2a).

The size (or energy capacity) of an explosion will also be a large factor in the size of the resultant spatter field. A small, or low energy, explosion may not make it out of the crater, and therefore not create much of a spatter field. The size of an explosion and depth of crater go hand-in-hand in this respect, as a deeper crater will require an explosion of higher energy to create a detectable spatter field.

\subsubsection{Cooling rate}

While spatter fields are the source of the thermal signals they will cool quickly due to the high surface area of the bombs and ejecta combined with any environmental effects (wind, rain, crater geometry). Modeled explosions as well as explosions at Stromboli Volcano during the 2010 field campaign were seen to cool below the detection threshold of thermal imagery within seconds to a few minutes. This rapid reduction of the thermal signal greatly limits the ability of satellite detection of these events. A spatter field produced from a small scale explosion will only stay hot for a short amount of time, a minute or two (Harris et al., 2013). As an example, a volcano with 70 explosions per day will have hot material visible on the surface for approximately $70-140 \mathrm{~min}$, or $\sim 5-10 \%$ of the day. As this is a very small portion of the day, it is understandable that not all explosions will be seen by satellite imagery. However, by analyzing the number of explosions imaged and observing a volcano with multiple ground based sensors, the percentage of explosions seen in satellite data each day can be determined.

The duration of an explosion will play a part in determining the cooling rate of the spatter field. In some cases and explosion would deposit material for up to $30 \mathrm{~s}$ to $1 \mathrm{~min}$. The thermal signal from these explosions would not only include the cooling spatter field, but would incorporate all the time during the explosion when hot material is constantly being supplied. There were very few of these explosions measured at Stromboli during the 2010 field campaign, but they occur at other volcanoes with different vent geometry and conduit conditions.

\section{Materials and methods}

\subsection{Materials}

\subsubsection{Satellite data}

NASA's Moderate Resolution Imaging Spectroradiometer (MODIS) is a sensor aboard the polar orbiting Earth Observing System (EOS) satellites Terra and Aqua. MODIS collects data in 36 spectral bands from $0.62 \mu \mathrm{m}-14.385 \mu \mathrm{m}$. Two subsets of this spectral window collect images in the thermal- and mid-infrared wavelengths and are used for the detection of thermal features on the ground (Wright et al., 2004; Dehn and Harris, in press). Bands 20-22 collect data from $3.66 \mu \mathrm{m}$ to $3.989 \mu \mathrm{m}$ and bands 31 and 32 collect data from $10.78 \mu \mathrm{m}$ to $12.27 \mu \mathrm{m}$ (NASA MODIS Web, 2013). The MODIS sensors have a temporal resolution that images the entire surface of Earth every one to two days. This provides approximately 3-6 images a day at Stromboli (LP DAAC MODIS Overview, 2013).

The Advanced Spaceborne Thermal Emission and Reflection Radiometer (ASTER) is a US/Japan designed sensor also aboard NASA's EOS Terra satellite. Because this sensor is co-located with a MODIS sensor, time coincident images can be captured from this satellite. ASTER is equipped to collect data in 15 spectral bands from $0.52 \mu \mathrm{m}$ to $11.65 \mu \mathrm{m}$. The short-wave infrared (SWIR) bands (measuring from $1.6 \mu \mathrm{m}$ to $2.43 \mu \mathrm{m}$ ) are no longer functioning on ASTER with data only available prior to April, 2008 (NASA/JPL, 2009). This data can be used for retrospective analysis of very hot targets. The long-wave (thermal) infrared bands (TIR_Band 10-14) are still collecting data at $8.125 \mu \mathrm{m}-$ $11.65 \mu \mathrm{m}$, which is a spectral window comparable to some of the infrared bands collected by MODIS (Abrams et al., 2002). The ASTER sensor is a tasked sensor, meaning that it only records images when they are requested (Duda et al., 2009). At times of elevated volcanic activity the ASTER sensor can be scheduled to capture imagery of the area (NASA ASTER Urgent Request Protocol) (Duda et al., 2009). This was carried out at Stromboli in 2003 and 2006 during the larger eruptions which included explosive activity, ash plumes, and lava flows. (LP DAAC ASTER Overview, 2013).

2.1.1.1. Spatial resolution and pixel averaging. The MODIS data used has a satellite pixel size of $1 \mathrm{~km}$ at nadir (Fig. 3a). As the sensor moves from 

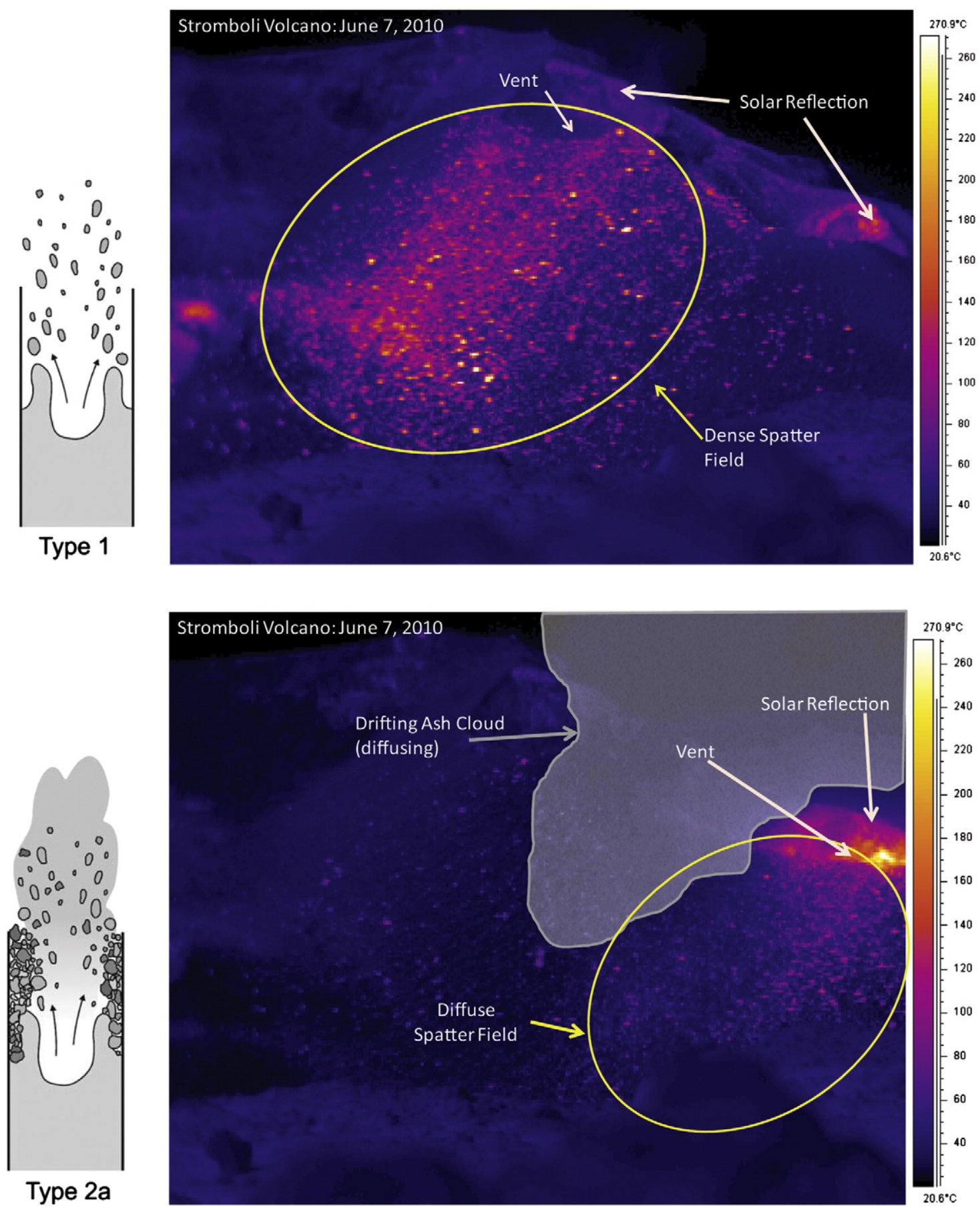

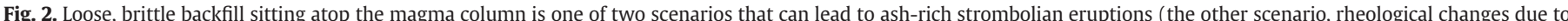

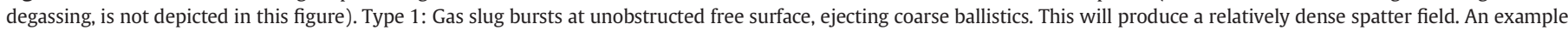

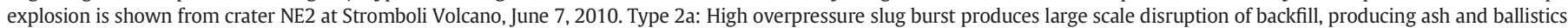

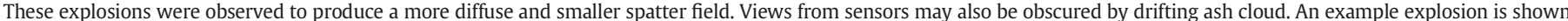
from crater NE1 at Stromboli Volcano, June 7, 2010 (diagrams modified from Patrick et al., 2007).

nadir, the pixel size will be distorted (Patrick, 2002; Lillesand et al., 2008). Stromboli Island has a surface area of about $12.5 \mathrm{~km}$ and is represented by $12-15$ pixels (whole and partial) in each MODIS satellite image. For moderate and larger sized explosions (the majority of activity seen historically (GVN, 1989, 1991b, 1994, 2000)), this spatial resolution is adequate to detect a thermal signal, though the smallest explosions are likely missed. The size of a spatter field is a direct result of the size of the explosion, the existence or amount of crater infill, crater geometry, and the type of material erupted. Smaller explosions and deep craters will lead to less detectable spatter fields. The angle and velocity at which debris is erupted will impact the size and emplacement of the spatter fields (Fig. 3b); a smaller eruption angle will produce a smaller field, a low velocity explosion will cover less area and remain close to the vent. The topography of the volcanic edifice will influence a spatter field and how it is imaged by a sensor. Steeply sloping flanks combined with a varying look angle can lead to differing degrees of pixel distortion (Dehn et al., 2000).

The ASTER sensor has a spatial resolution of $90 \mathrm{~m}$ (at nadir) in the bands used for the detection of volcanic thermal anomalies (Fig. 3a). This creates a counter problem from the lower resolution satellites, in 

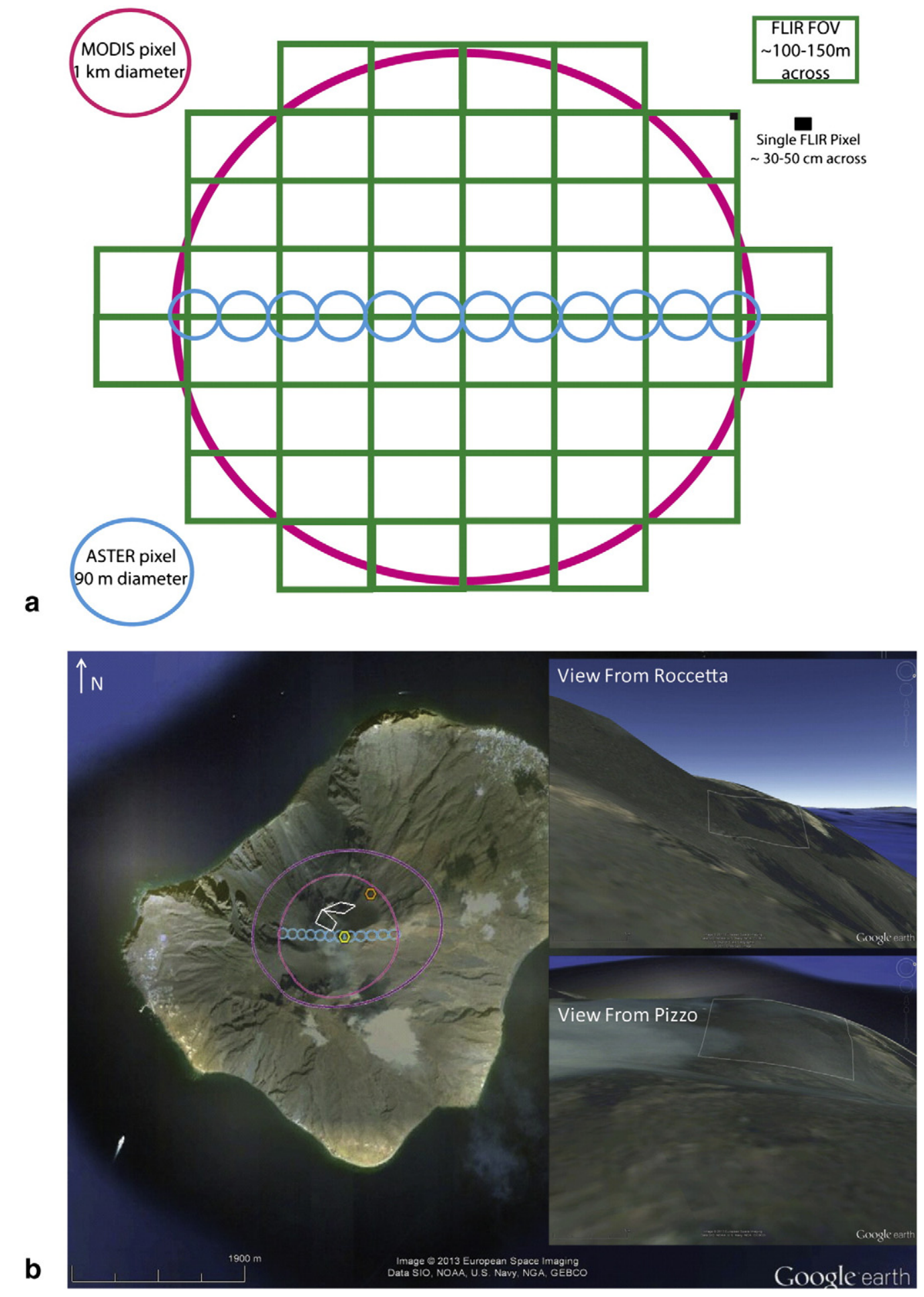

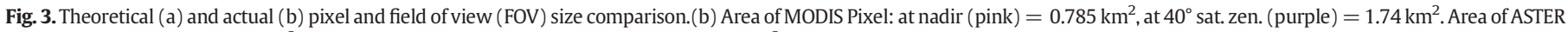

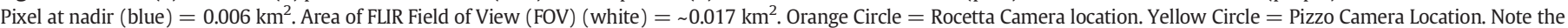

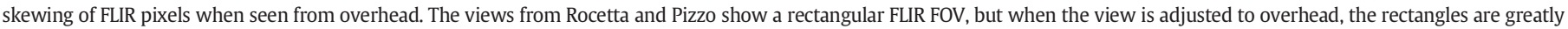
skewed due to topographic effects.

that as this resolution is so small it will almost always show hot pixels related to elevated ground temperature unassociated with eruptions, fumaroles, degassing, and cooling material (Harris and Stevenson, 1997). This occurs because the smaller resolution means that more area of each pixel will be filled with the hot target and so the pixel averaging (if any) will result in a much warmer temperature. In some locations, this is a big help in detecting thermal activity. However, at Stromboli, it can be a hindrance as the activity is frequent and there are many constantly active fumarolic vents (Harris and Stevenson, 1997; Harris and Ripepe, 2007).

One important factor to consider when discussing the spatial coverage of the spatter fields is the process of satellite pixel averaging. When a sensor captures an image of an area, it breaks the information into pixels. The MODIS sensor represents thermal information in elliptical pixels of $1 \mathrm{~km}$ diameter $\left(0.785 \mathrm{~km}^{2}\right.$ area $)$. This means that the temperatures of any features within that pixels area will be averaged to 
produce the single temperature value assigned to that pixel. For example, if there is a cool $\left(0{ }^{\circ} \mathrm{C}\right)$ background covering $0.735 \mathrm{~km}^{2}$ and a small hot $\left(500{ }^{\circ} \mathrm{C}\right)$ feature, like a lava flow, covering the remaining $0.05 \mathrm{~km}^{2}$, a pixel temperature value of only $25^{\circ} \mathrm{C}$ will occur.

\subsubsection{Thermal camera imagery}

A FLIR (Forward Looking Infrared Radiometer) Systems ThermaCAM $^{\mathrm{TM}}$ S40 camera was used from May 29 to June 9, 2010 to record explosions from craters NE1 and NE2 at Stromboli Volcano in Italy (Fig. 1). The camera uses an uncooled microbolometer to detect and record images in a thermal band at 7.5-13 $\mu \mathrm{m}$ and at a temperature range of $0-500{ }^{\circ} \mathrm{C}$ and frequency of $7.5 \mathrm{~Hz}$. The camera was located at multiple locations at a distance of $250-400 \mathrm{~m}$ from the active vents, producing a field of view (FOV) ranging $(320 \times 240$ pixel $)$ from 100 to $150 \mathrm{~m}$ across with a single pixel measuring $33.2-53.1 \mathrm{~cm}$ across, respectively (Fig. 3b and Fig. 4). The camera was focused so that the FOV would capture the volcano flank and spatter field with little of the image taken up by sky. Approximately 130 explosions were recorded and analyzed.

Thermal camera images were also obtained from periods during the summers of 2002, 2003, and 2008 (see Calvari et al., 2005; Harris et al., 2005; Patrick et al., 2007). Though these images are not used here for specific spatter field analysis (due to frame of view focus), they are used to compare location and magnitude of explosive activity at Stromboli over the years, thus enhancing the temporal resolution of the dataset collected in 2010.

\subsubsection{Other data}

At Stromboli Volcano, there is a long, near-continuous, record of seismic and infrasonic activity (Neuberg and Luckett, 1996; Harris and
Ripepe, 2007; Ripepe et al., 2007) as well as an analog recording of thermal activity from the north-east (NE) vents since 2003 recorded by the Dipartimento di Scienze della Terra at Universita di Firenze (UF) (Ripepe et al., 2008). The network deployed and utilized by the Scienze della Terra at UF currently operates four seismo-acoustic stations (Neuberg and Luckett, 1996), two thermal imaging cameras (Ripepe et al., 2008), three tilt-meters, one weather station, a five element infrasound array, 2 geochemical/radon sensors, and one wave monitoring sensor located off the coast of Punta dei Corvi (UF, 2013) Data is collected from these sensors and is then reported in an information release by Universita degli Studi di Firenze, Departmento di Scienze delle Terra. This extensive multi-disciplinary network allows the best use of the limited satellite data for the statistical method of frequency detection, which will be discussed here, along with the known record of explosive activity to map out a comprehensive history of volcanic activity at Stromboli.

The thermal cameras used by UF are focused on the area above the vents to capture explosions, not necessarily the area where the spatter fields are deposited. For this study, no actual data collected by this network is used directly, but the frequency counts from the eruption reports are used to fill in a background data set for Stromboli (see time series in Fig. 5). This assists the analysis to create a more robust time series as well as to allow detection of changes in activity before, during, and after the two paroxysms to be examined at Stromboli when our satellite datasets are sparse.

The number of explosions per day are reported and counted by using the thermal camera and seismic data each day. Fig. 4 has been populated by using these daily event counts to create a time series covering all the activity since the implementation of the monitoring system (as set up by UF, Instituto Nazionale di Geofisica e Vulcanologia (Osservatorio

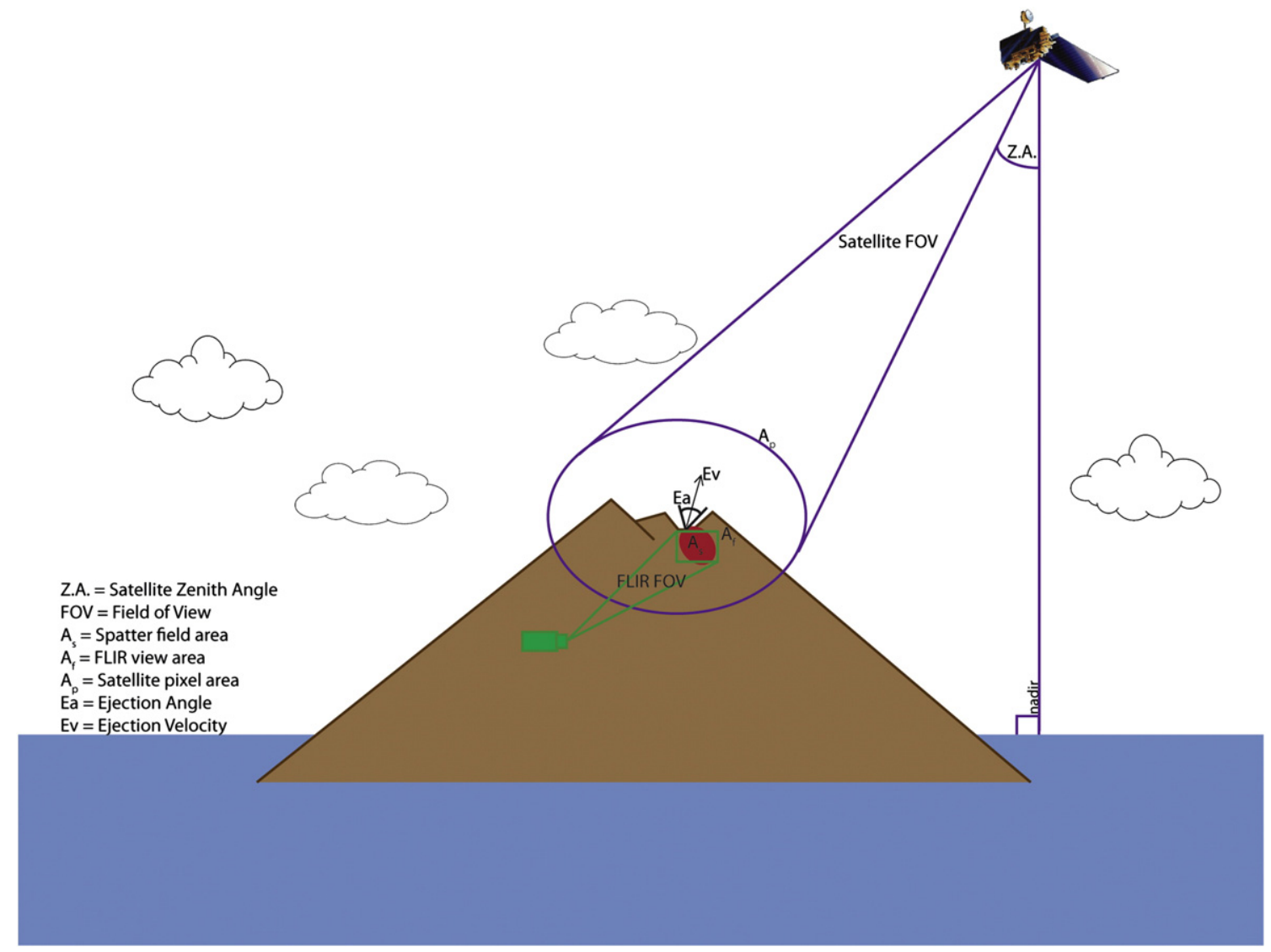

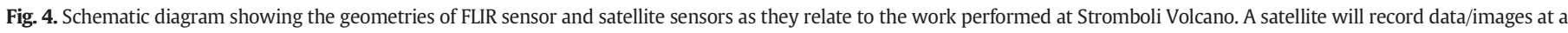

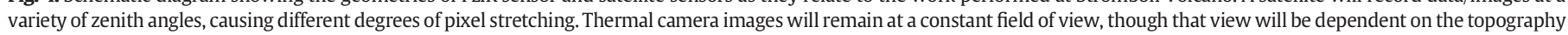
of the area of interest. Pixel stretching due to zenith angle can also be seen in Fig. $2 \mathrm{~b}$. 


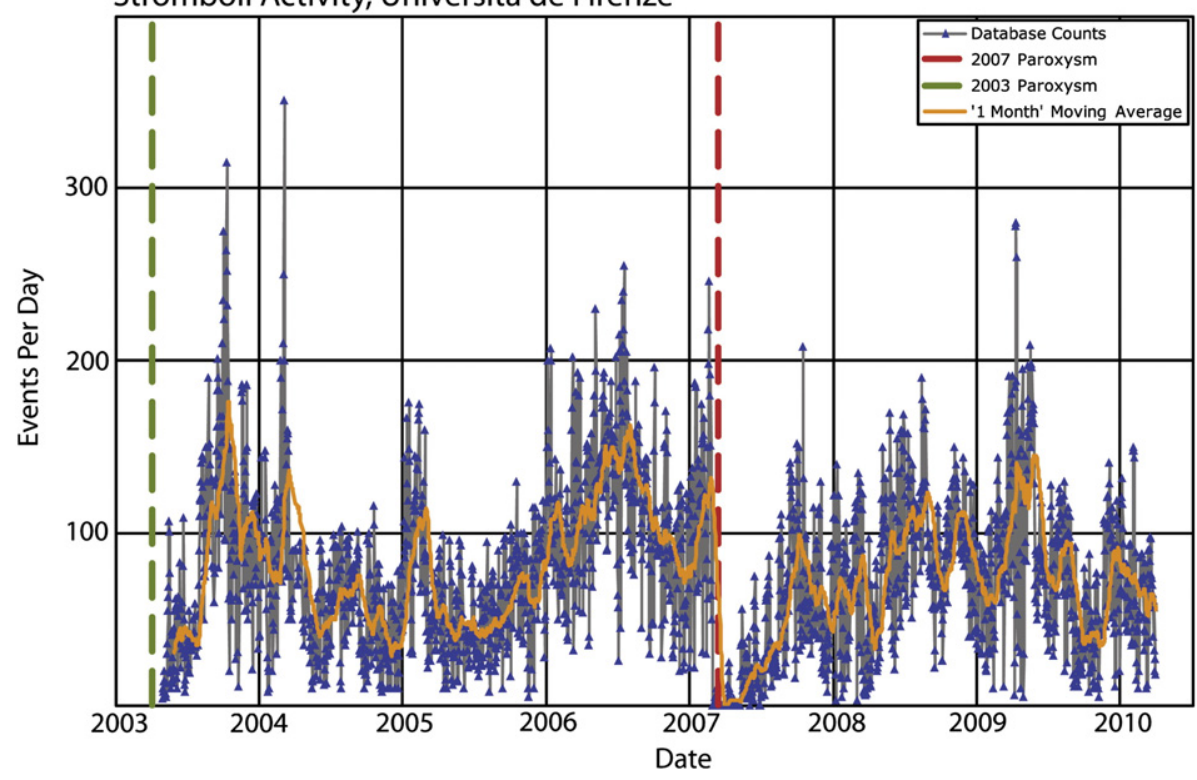

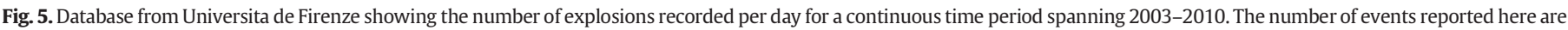

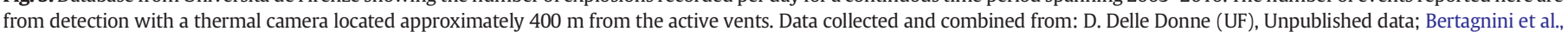

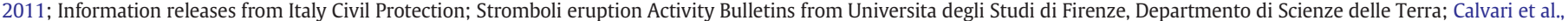
2006; Rosi et al., 2006; Ripepe and Harris, 2008.

Vesuviano), and others). Some trends are clearly evident in this data, such as the lead up to and occurrence of paroxysmal episodes. Paroxysms cause a complete cessation of small scale explosive activity in both 2003 (April 5) and 2007 (March 15) (Bertagnini et al., 2011). Explosive frequency tends to increase until periods of paroxysmal activity when small explosions completely stop. When explosive activity resumes, there are few explosions per day and numbers increase steadily over time until they reach typical background levels of activity, roughly 75-125 explosions per day (Fig. 5).

The counts reported by UF are not an absolute number of explosions, as the thermal camera only viewed a portion of the active vents and small explosions can go undetected. Hence, the UF data would give a decreased number of explosions. The seismic instruments deployed by UF, INGV, and others (Neuberg et al., 1994; Marchetti and Ripepe, 2005) certainly detect events that are too small to be seen in thermal satellite or FLIR data. These events may in fact not breach the crater rim (occurring within the conduit or under a significant amount of crater infill), resulting in an elevated seismic event count relative to other datasets (Table 1 ).

\subsection{Methods}

\subsubsection{Database retrieval}

The University of Alaska, Fairbanks (UAF) and the Geographic Information Network of Alaska (GINA) have a large database of archived

Table 1

Detection statistics for multiple methods at Stromboli showing average number of events per day during periods of possible monitoring. The discrepancy between numbers reflects the capability of different methods in the detection of small scale explosion. Discrepancies consist of (but are not limited to) spatial resolution, temporal resolution, field of view, and instrument sensitivity (data compiled from: Stromboli eruption Activity Bulletins from Universita degli Studi di Firenze, Departmento di Scienze delle Terra; this study; UAF/GINA satellite image database).

\begin{tabular}{ll}
\hline Sensor & Average \# of events per day \\
\hline Thermal camera (UF) & 77 (24 h/day over 7 years) \\
Thermal camera (this study) & $\begin{array}{l}146 \text { (extrapolated from } 5 \text { days of recorded } \\
\text { explosions) }\end{array}$ \\
MODIS satellite sensor (this study) & 0.35 (available database data) \\
\hline
\end{tabular}

satellite imagery from the Advance Very High Resolution Radiometer (AVHRR) and MODIS sensors, mainly centered on North Pacific volcanoes (Dean et al., 2002). However, there is also a subset of MODIS and ASTER data from Stromboli Volcano including data from the time periods listed in Table 2 .

When developing a method for detecting changes in frequency of small explosions or explosive activity at a volcano, the ability to sample and analyze from a continuous dataset covering many years is a key component. However, in many cases this is not possible. For Stromboli Volcano, the UAF/GINA catalog consists of a large amount of data over many years, though not continuously. This data was used in this study with the knowledge of the data omissions and the wealth of other instrumentation on the island. Ideally MODIS data would have been collected over the entire 8 years included in this study, though only $22 \%$ of these days are available in the archive.

All metadata for the satellite imagery was accessed and downloaded from UAF/Geophysical Institute (GI)/Alaska Volcano Observatory (AVO) online archive. For Stromboli, this included the satellite identification, date and time of acquisition, but no data about pixel properties. All images were viewed and analyzed in the UAF-GI/AVO online remote sensing webtools $40 \times 40$ viewer (see description in Dehn et al., 2000; Dean et al., 2002; Webley et al., 2009). This tool shows a 40 pixel by 40 pixel view centered on the georeferenced location of the target volcano. The tool gives information on all spectral bands of each sensor as well as a number of band subtraction products used to indicate ash plumes, removal solar influence, and highlight thermal features, Table 3.

Table 2

Available data/images of Stromboli Volcano in the UAF/GINA satellite image database.

\begin{tabular}{lll}
\hline Sensor & Year & Dates \\
\hline MODIS & 2002 & October 23-December 31 \\
& 2004 & September 7-March 30 \\
& 2006 & Full Year \\
& 2009 & February 19-March 3, \\
& & May 19, November 29 \\
ASTER & 2003 & February 23 \\
& 2006 & March 13 \\
& & April 13 \\
& November 16 \\
\hline
\end{tabular}


Table 3

Band math products in UAF-GI/AVO webtools and/or UAF/GINA satellite imagery database. For MODVOLC methods see Wright et al., 2004, BTD method as described in Prata, 1989a,b; Corradini et al., 2008; Webley et al., 2009. Solar influence methodology based on method described in Dozier, 1981.

\begin{tabular}{lll}
\hline Name & Band math & Purpose \\
\hline 20a21 & B20 = saturation, then B21 & 20 unless saturated, then 21 \\
20 m31 & B20-B31 & Mitigate solar influence \\
20nd32 & B20-B32/B20 + B32 & Similar to MODVOLC method \\
22nd32 & B21-B32/B21 + B32 & Similar to MODVOLC method \\
31 m32 & B31-B32 & Ash detection, BTD method \\
\hline
\end{tabular}

\subsubsection{Development of processing routine}

Multiple steps were applied to the original dataset in order to cull the data to relevant and viable images. The MODIS data for Stromboli Volcano included information on acquisition date and time, viewing geometry, and spectral bands 12, 17, 20, 21, 22, 28, 29, 30, 31, and 32 . Further processing is automatically done to create a number of band math images listed in Table 3. The original datasets contained 2065 images recorded over 653 days from 2002 to 2009. In some cases, duplicate images are saved separately. These images are removed to reduce the chance of double identification of thermal features. The remaining images were then subjected to a number of character tests, described below, to ensure the data can be used in a statistical monitoring method.

Each satellite image has a unique set of geometries that can affect the detectability of features on Earth's surface. For this study, the most critical of these geometries is the satellite zenith angle (Fig. 4)-or the angle from nadir at which the satellite is viewing the volcano. There is a correlation between the satellite zenith angle and the geometry of the actual pixels in any given image (Patrick, 2002; Patrick et al., 2005; Lillesand et al., 2008). As the zenith angle increases the individual pixels become 'stretched'. A MODIS pixel at nadir has a $1 \mathrm{~km}$ diameter, but when viewed at a satellite zenith angle of $40^{\circ}$, the pixels dimensions change to roughly $1.7 \mathrm{~km}$ by $1.3 \mathrm{~km}$ (increasing the pixel area from $0.79 \mathrm{~km}^{2}$ to $1.74 \mathrm{~km}^{2}$ ). When the zenith angle exceeds $40^{\circ}$, the pixels will overlap to a point where unique data is no longer adequately represented, as illustrated by Patrick et al. (2005). All data acquired at a satellite zenith angle higher than $40^{\circ}$ was removed from the dataset (Patrick et al., 2005; Dehn and Harris, in press).

The geometry of the volcanic edifice and crater will also dictate viable zenith angles. In cases of a high zenith angle, the sensor may not be able to detect thermal signals from within a volcanic crater. An ideal zenith angle would be close to zero, or nadir, indicating that the sensor is directly above the volcano. The eruptive vents at Stromboli Volcano each sit in a shallow crater within and around a larger summit depression. Due to the shallowness of the crater a larger zenith angle will still produce useful imagery. All data acquired at a satellite zenith angle higher than $30^{\circ}$ was removed from the dataset.

This analysis method required that each image be individually analyzed to ensure that any anomalous feature would be tagged, as well as offering the ability to determine the weather and other atmospheric factors that could affect each image. Weather is a significant hindrance, when viewing thermal infrared data, as the wavelengths in these bands cannot detect thermal signals from the ground surface through clouds or heavy water vapor (Watson and Prakash, in press). Weather for each image was evaluated on a graded scale as clear (95), mostly clear (75), partly cloudy (50), mostly cloudy (25), cloudy (5), and NAN (0) for any data that was unusable due to pixel corruption and noise. After this step, a weather statistic was calculated by creating a weighted average of the assigned grades and the number of images on a weekly basis. This statistic was then used to calculate the probability of detecting a thermal anomaly in the satellite data and to assist in weighting weather compromised images.

The remaining images were then individually analyzed for thermal anomalies. While thermal anomalies were selected mainly by manual analysis and visual recognition, reviewing of several images verified that observed anomalies tended to be a pixel or group of pixels with a temperature $\sim 5-10\left({ }^{\circ} \mathrm{C}\right)$ above the background temperature. Images were grouped by week and the number of thermal anomalies was summed for the entire week. The final dataset consisted of $33.6 \%$ of the original images found in the UAF/GINA database and had 227 observed anomalies out of 694 images (Table 4).

\subsubsection{Statistical analysis}

Once all of the images have been individually analyzed, the collected information was used to produce a statistical matrix of the estimated number of explosions per day and per week. These calculations and statistical data take into account the weather, the number of observed explosions, the number of passes, residence time of the sensor, and cooling rate of a spatter field.

The first step of the statistical portion of this study was to use the weather grade assigned to each image to calculate a weighted average for a week's worth of data at a time. This weather statistic is used to calculate an estimate for the amount of minutes per week a satellite has a good/clear view of the volcano. This is calculated by multiplying the number of satellite passes per week by the weather statistic, and then multiplying this by the residence time of the spatter field, i.e. the amount of time that a sensor could detect the hot target (Eq. (1)). From this point, the minimum and optimal number of events per week can be determined. The minimum number of events per week is the number of observed thermal anomalies in the data. The optimal number of events is an estimated number based on the minimum number of events, the amount of good satellite views per week, and the number of minutes in a week (Eq. (2)). The minimum number and optimal number of events are then averaged and this is the estimated average number of events per week (Eq. (3)) value that is reported in the Results section and Fig. 6.

$$
\begin{aligned}
& \text { Satellite Minutes Per Week } \\
& \quad=\left(\left[(\# \text { PassesPerWeek }) \times\left(\frac{\text { WeatherStatistic }}{100}\right)\right] \times \text { ResidenceTime }\right)
\end{aligned}
$$

Optimal Events Per Week $=\frac{\text { MinimumEventsPerWeek }}{(\text { SatelliteMinutesPerWeek } /[24 \times 60 \times 7])}$

Average Events Per Week

$=\frac{(\text { MinimumEventsPerWeek } \times \text { OptimalEventsPerWeek })}{2}$

Table 4

Results from multiple steps of the processing routine showing the number of MODIS images for Stromboli through steps of data clipping, from initial data to usable image and observed thermal anomalies. SZSwath for Stromboli was set at $40^{\circ}$ from nadir and

\begin{tabular}{|c|c|c|c|c|c|c|}
\hline Year & Days w/ data & $\begin{array}{l}\text { Initial } \\
\text { images }\end{array}$ & $\begin{array}{l}\text { SZSwath } \\
\text { clip }\end{array}$ & $\begin{array}{l}\text { SZCrater } \\
\text { clip }\end{array}$ & $\begin{array}{l}\% \text { of } \\
\text { Initial } \\
\text { images }\end{array}$ & $\begin{array}{l}\text { Observed } \\
\text { thermal } \\
\text { anomalies }\end{array}$ \\
\hline 2002 & 69 & 301 & 132 & 100 & $33.2 \%$ & 37 \\
\hline 2003 & No data & No data & No data & No data & No data & No data \\
\hline 2004 & 115 & 152 & 87 & 65 & $42.7 \%$ & 9 \\
\hline 2005 & 90 & 130 & 56 & 43 & $33.1 \%$ & 12 \\
\hline 2006 & 365 & 1465 & 656 & 482 & $32.9 \%$ & 167 \\
\hline 2007 & No data & No data & No data & No data & No data & No data \\
\hline 2008 & No data & No data & No data & No data & No data & No data \\
\hline 2009 & 14 & 17 & 6 & 4 & $24 \%$ & 2 \\
\hline Total & 653 & 2065 & 937 & 694 & $33.6 \%$ & 227 \\
\hline
\end{tabular}
SZCrater at $30^{\circ}$. 


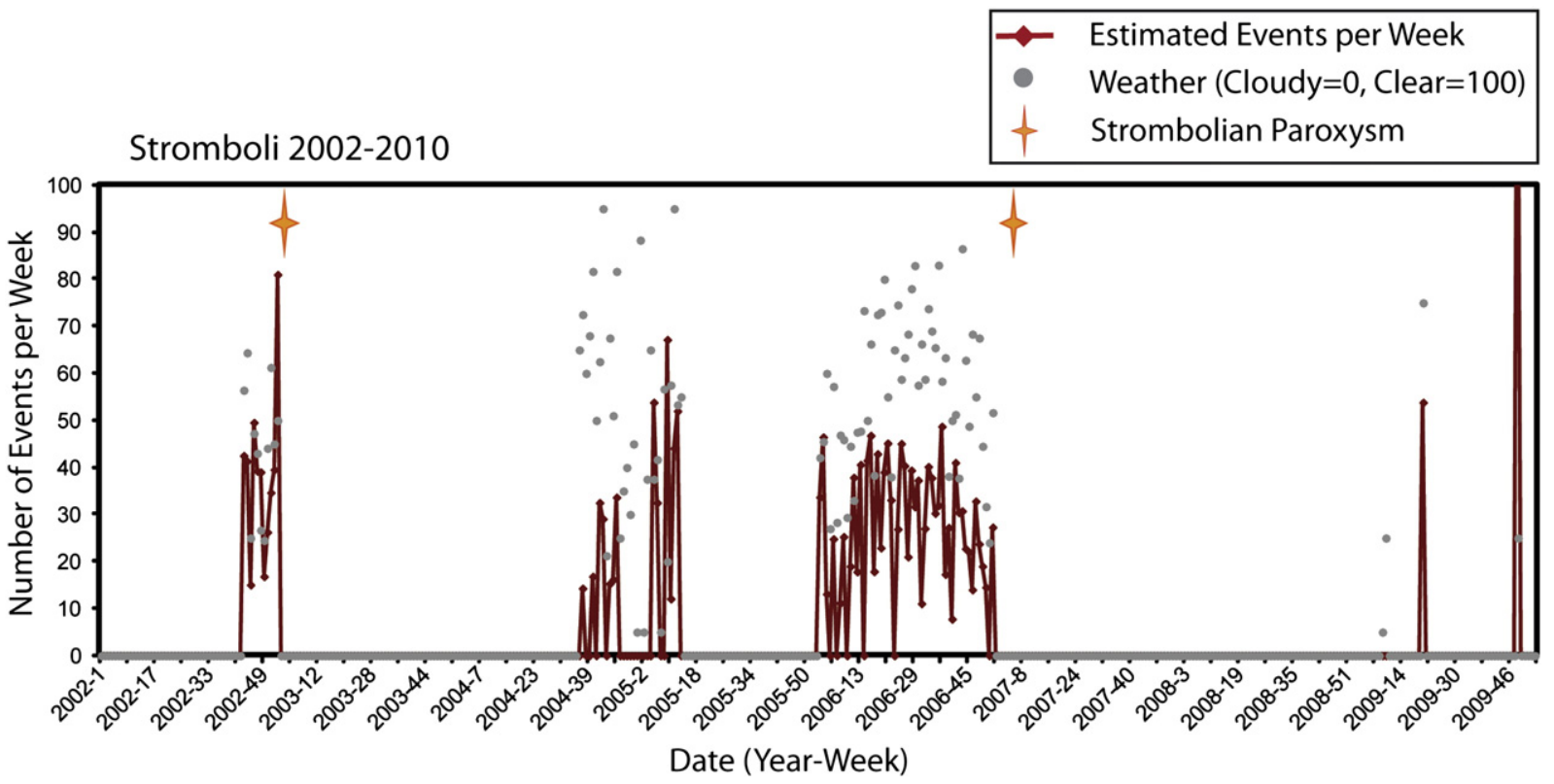

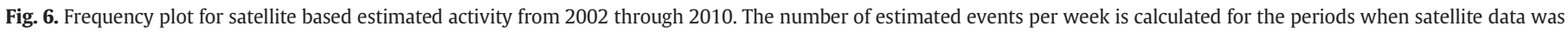
available; leaving gaps where data was absent (no effort was made to determine explosive frequency when no satellite data was available).

\subsubsection{Thermal Camera and Satellite Comparisons}

In order to verify the ability of the satellite sensors to detect spatter fields, the thermal flux was calculated for the detectable thresholds of the sensors used and for a selection spatter fields recorded with the thermal camera. An explosion can only be detected by satellite sensors if the thermal output is high enough to overcome the detection threshold. Each satellite has a different thermal detection threshold, based on wavelength measured, pixel size, and temperature of the target area. The detection capability of the satellite sensor is calculated using a modified Planck function (Eq. (4)) (Kreith and Bohn, 1993).

$E_{b \lambda}=A_{\text {pix }} \times\left\{\left(\frac{8 \pi h c}{\lambda^{5}}\right) \times\left[\frac{1}{\left(\left(e^{h c} / \lambda k T\right)-1\right)}\right]\right\}$

where $E_{b \lambda}$ is the radiance measured by the satellite, $A_{p i x}$ is the area of the satellite pixel, $h$ is Planck's constant $\left(6.6260689633 \times 10^{-34}\right), c$ is the speed of light $\left(3.00 \times 10^{8}\right), \lambda$ is the wavelength measured $(1.10$ $\times 10^{-5}$ ), and $T$ is the temperature of target pixel.

When examining the thermal camera video data a different method is used to calculate the irradiance from the spatter fields. This is performed using the radiant energy equation (Eq. (5)) (Kreith and Bohn, 1993). This number (irradiance) is a measurement of the amount or thermal energy reflected from an object in all directions (Kreith and Bohn, 1993). While each particle in a spatter field will produce a thermal signal, all particles are summed to produce a thermal flux for the entire field. This thermal flux will also include non-thermally anomalous areas (background) and the ambient temperature of this area.

$Q_{r}=\sigma \varepsilon \tau \varphi A\left(T_{h}^{4}-T_{c}^{4}\right)$

where $Q_{r}$ is the radiative heat measured by the thermal camera, $\sigma$ is the Stefan-Boltzmann constant $\left(5.6704 \times 10^{-8}\right), \varepsilon$ is the emissivity $(0.95)$, $\tau$ is the atmospheric transmissivity (accounted for by FLIR internal corrections for temperature), $\varphi$ is the shape factor (ignored for this work), $A$ is the area of spatter field (including interstitial background area), $T_{h}$ is the temperature of hot material, and $T_{c}$ is the background temperature.
Then Eqs. (4) and (5) are used to calculate the irradiance and the radiance of a thermal feature. In order to compare the radiance calculated for the satellite sensors thermal detection thresholds and the irradiance (thermal output) calculated for the FLIR data spatter fields, the irradiance is converted from a lambertian (in all directions) reflector to a per steradian (in one specific ray path) reflector (Eq. (6)).

$E_{b \lambda}=Q_{r} \times(1 / 2 \times 12.57)$

\section{Results}

\subsection{Spatter field measurements}

During the field campaign, 130 explosions from 2 vents (NE1 and NE2) were recorded using the FLIR thermal camera. The majority of explosions were Type 1 (Patrick et al., 2007, Fig. 2) and produced spatter fields. There were also a number of Type $2 \mathrm{a}$ explosions, also producing spatter fields (Fig. 2). There were very few Type $2 \mathrm{~b}$ explosions during the recording period, and as these explosions produce no spatter field, they are not used for this study.

Spatter fields from NE2 ranged from $9 \mathrm{~m}$ to $105 \mathrm{~m}$ diameter (average diameter of $54 \mathrm{~m}$ ). The material from an average sized explosion had a spatial distribution of around $2300 \mathrm{~m}^{2}$ with material covering 15-20\% of that area. The explosions that were measured from NE1 range in diameter from $7 \mathrm{~m}$ to $135 \mathrm{~m}$ (average diameter of $48 \mathrm{~m}$ ). Spatter fields were mostly located within the crater at Stromboli, though some explosions (mainly from NE1) did send material down the Sciarra del Fuoco (see location in Fig. 1). Sciara focused explosions pose a difficulty in measurement due to the obliqueness of the camera angle and because the vast majority of material continually rolls down the slope, dispersing and therefore 'dimming' (effectively cooling) the spatter field. This steeper slope also geometrically constrains the view, making a smaller target for an overhead view (from a satellite).

\subsubsection{Spatter field thermal flux}

The thermal flux was calculated for 38 explosions spread over 4 days from multiple locations and look angles using Eqs. (4) and (5) (Table 5a). Thermal flux was calculated for two periods of time during 
Table 5a

Radiance values for two points in time during the eruption and cooling of spatter fields.

\begin{tabular}{lll}
\hline Camera location & $\begin{array}{l}\text { Average radiance at maximum } \\
\text { temperature }\end{array}$ & $\begin{array}{l}\text { Average radiance at } 60 \mathrm{~s} \\
\text { post-eruption }\end{array}$ \\
\hline Ladybug & $8.46 \times 10^{5} \mathrm{~W} \mathrm{sr}^{-1} \mathrm{~m}^{-3}$ & $1.57 \times 10^{5} \mathrm{~W} \mathrm{sr}^{-1} \mathrm{~m}^{-3}$ \\
Pizzo & $3.6 \times 10^{6} \mathrm{~W} \mathrm{sr}^{-1} \mathrm{~m}^{-3}$ & $9.61 \times 10^{5} \mathrm{~W} \mathrm{sr}-1 \mathrm{~m}^{-3}$ \\
SPSN1 & $1.55 \times 10^{6} \mathrm{~W} \mathrm{sr}^{-1} \mathrm{~m}^{-3}$ & $1.49 \times 10^{5} \mathrm{~W} \mathrm{sr}^{-1} \mathrm{~m}^{-3}$ \\
SPSN2 & $9.83 \times 10^{5} \mathrm{~W} \mathrm{sr}^{-1} \mathrm{~m}^{-3}$ & $1.44 \times 10^{5} \mathrm{~W} \mathrm{sr}^{-1} \mathrm{~m}^{-3}$ \\
\hline
\end{tabular}

each explosion; the time of the maximum temperature reading and then again $60 \mathrm{~s}$ after the point of maximum temperature. This will assist in determining the factor that cooling rate plays in the detection of spatter fields by satellite sensors. The detection thresholds of the satellites used were also calculated in order to determine if spatter fields would be visible (Table $5 b)$.

When comparing spatter field radiance to the detectable thresholds of the satellite, initially, almost all spatter fields have radiances exceeding satellite thresholds. After sixty seconds, the spatter fields have cooled to a point where only the very largest explosions, generally emplaced on a gently sloping surface, are still visible by satellite detection methods.

\subsection{Results of statistical analysis}

The results of the processing routine are reported in Table 4. After data clipping steps, $33 \%$ of the original data set was used in the statistical analysis. By plotting the statistical analysis results over time, an estimate of the number of events per week is shown (Fig. 6). This estimate shows the relative frequency of explosions and can indicate changes in the character of the volcanic activity. The number of estimated events per week is calculated for the periods when satellite data was available; leaving gaps where data was absent (The capability to determine explosive frequency when no satellite data was available was beyond the capabilities of this current study). The weather for the area and two instances of strombolian Paroxysms are also plotted in Fig. 6. These paroxysms represent two periods of time when there was heightened volcanic activity at Stromboli Volcano, resulting in large explosions, ash columns and plumes, and lava flows (Harris et al., 2008; Bertolaso et al., 2009; Bertagnini et al., 2011). The two paroxysms are important as they match up with changes in activity. Prior to each paroxysm regular strombolian activity first increases in frequency and then ceases completely. This occurred in both 2002-2003 and 2007 eruptions and may be a key indicator of future paroxysms. If monitoring based on the above method is continued, it may be possible to see when the frequency of explosions changes and determine possible upcoming paroxysmal events. The trends detected using the single-source satellite method (Fig. 6) match trends in activity seen in the larger source time series (Fig. 5).

\section{Discussion}

\subsection{Feasibility of method}

When using data collected in the past to determine possible future activity, this method of monitoring volcanic activity proves to be fairly useful. There are a number of requirements in order for high quality data and statistically significant results to be produced and one must

\section{Table 5b}

Detection thresholds for MODIS and ASTER sensors. Spatter fields must have a radiance which exceeds these thresholds in order to be detected.

\begin{tabular}{ll}
\hline Sensor & Detectability thresholds \\
\hline MODIS & $2.23 \times 10^{5} \mathrm{~W} \mathrm{sr}^{-1} \mathrm{~m}^{-3}$ \\
ASTER & $1.71 \times 10^{3} \mathrm{~W} \mathrm{sr}^{-1} \mathrm{~m}^{-3}$ \\
\hline
\end{tabular}

acknowledge that all results are averages and/or estimates. This method does not specifically count discreet events at a volcano. However, it should be robust and internally consistent enough to provide a very good indication of the relative change of activity within a volcanic system; be it in frequency, size, temperature, or severity of events.

When used at Stromboli Volcano, the method was able to verify changes in activity prior to strombolian paroxysms and was able to replicate data determined using other ground-based sensors and personal observations and records. The ability to replicate other research methods is particularly useful because it means that this method can be adapted and used at volcanoes where no ground-based systems are present to provide some measure of monitoring, detection, and possibly forecasting. The link was reinforced between the cessation of small scale explosive activity and an impending paroxysm at Stromboli. This pattern was seen in the satellite data for both the 2003 and 2007 events and has been documented for multiple paroxysms in the history of Stromboli.

When the counts of explosions per day collected by UF (collected from thermal camera data) are compared to the average estimated number of explosions determined by the above described satellite method, the results show a correlation in the data (Fig. 7). The results must be scaled to account for the differing detection thresholds between thermal camera data and satellite derived data. The two sets of data show numerous correlations in peaks of activity. Though the satellite derived result was created using a non-continuous dataset, resulting in gaps where no data is available, for the periods of time when both data sets were populated the relative intensity of explosive activity are complimentary to one another.

A general idea of the type of activity typical of a volcano is an important factor in the application of this method. As developed here, the method is best fit to a volcano with frequent small scale explosive activity. While other infrequent types of activity will not necessarily degrade the information on small explosive frequency, more frequent cases of lava flows and large ash plumes may mask the smaller explosive events; in effect, over-saturating the method with continuous thermal data. Other factors that will affect the validity of application of this method are the availability of a continuous and continually populated dataset, appropriate sensor resolutions, a recorded history of the volcanoes previous activity, and, if available, some ground-based monitoring system (seismic, infrasound, thermal camera, webcam, etc.).

\subsection{Factors for a statistically valid methodology}

As mentioned above, there are a number of requirements for this method to produce high quality data, be statistically valid and reliably provide consistent analysis of the volcanic signals. Though not all factors are vital to the implementation of this method, they each enhance the value of data created.

\subsubsection{Continuous and continually populated dataset}

At Stromboli Volcano, only a partial dataset was used, with many time gaps in the satellite imagery. This meant a truly continuous time series of eruptive activity was not possible. However, at Stromboli, the presence of other monitoring systems filled in some of the temporal gaps and the well documented history and eruptive activity record indicated that the satellite data that was available covered periods prior to and following the major paroxysms.

At other locations where ground-based systems are not available, such as Cleveland Volcano in Alaska (AVO Website, 2013), it will be much more important to have a continuous satellite dataset. Any temporal gaps in data at these volcanoes will mean a complete absence of any data, and therefore no conclusions/assessments can be made about the eruptive activity during that time or for a period of time following renewed access to the satellite data. This continuous record is vital in the creation of a baseline of activity at a volcano. This baseline 
UF Thermal Detections vs Satellite Method Estimations

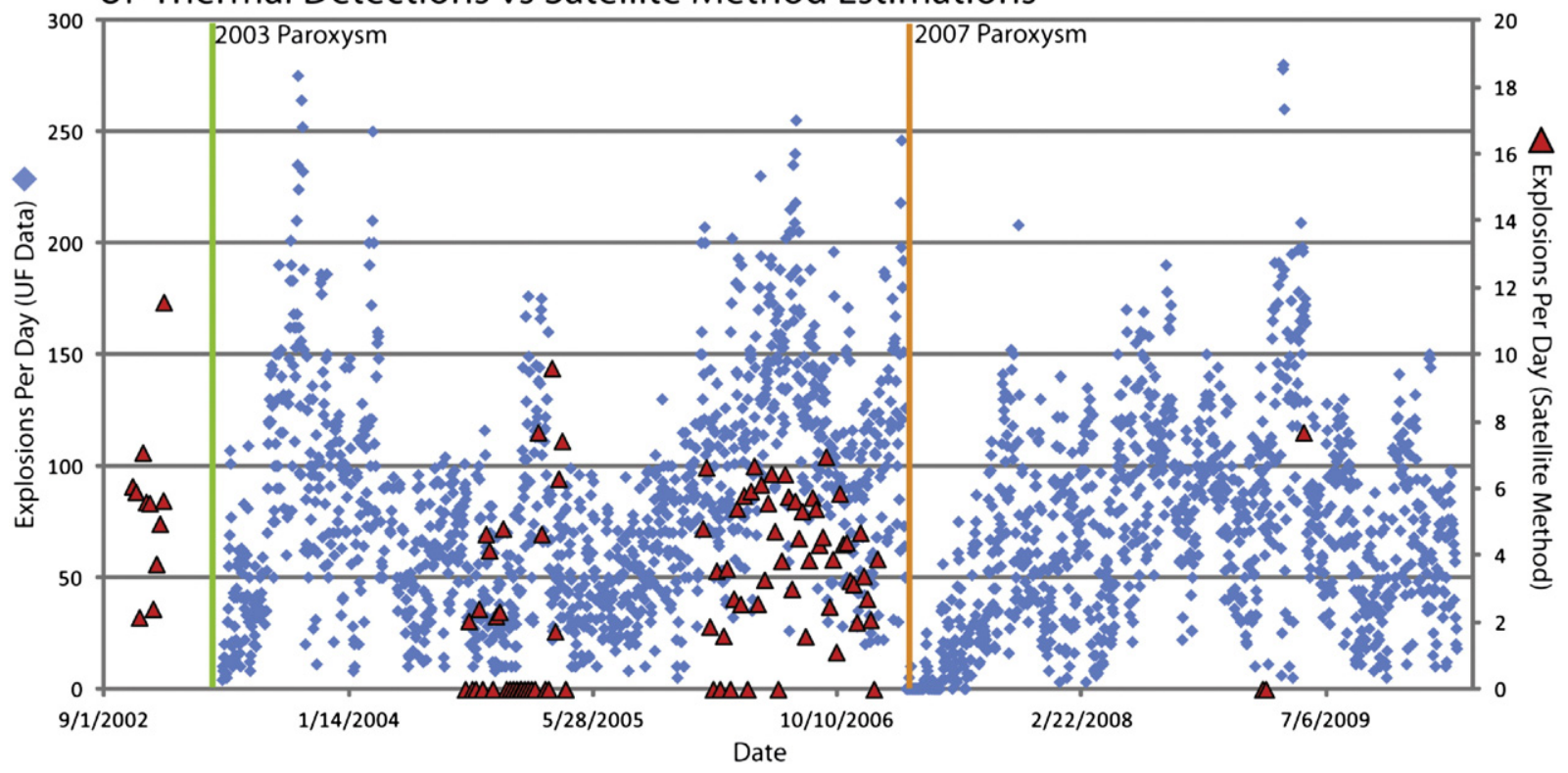

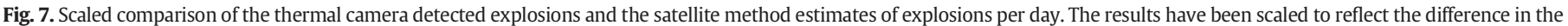
detection method; thermal camera detection has a lower threshold of detection than the satellite method, and will therefore detect higher activity rates.

will serve as a reference point to determine if there have been any significant changes in the behavior of the volcano.

One factor, nearly as important as a continuous dataset, is a database that is continually being updated with new data. Having background knowledge of the volcano and its activity levels allows for the creation and population of a historical time series. However, it hinders the ability to build an extensive future extrapolation of activity. With a continually populated database, new images can be analyzed and added to the time series to keep track of the current status of the volcano. As the background data is used to determine indications of changes in activity, the new activity can be analyzed to detect those indicators ahead of eruptive episodes.

\subsubsection{Appropriate satellite resolutions (spatial and temporal)}

Appropriate spatial and temporal resolutions are needed for the production of a robust time series. Spatial resolution will be mainly dependent upon the target volcano and its activity. Like at Stromboli, a volcano with constant fumarolic activity and frequent small explosions producing spatter fields, a small spatial resolution will not be very useful, as it will tend to show smaller and cooler thermal features than other sensors. A sensor with too coarse a spatial resolution will also be impractical as a small spatter field will be averaged across the larger pixel with too much cool background, and will not be detected as a thermally anomalous pixel.

The temporal resolution of a satellite is important in the creation of a continuous and robust dataset. If satellite overpasses are extremely limited, i.e. single passes with days in between, activity can easily go undetected completely or misidentified (if there is only a single image, a small lava flow may look similar to a spatter field or a small lava dome (Dehn et al., 2000)). For the work on Stromboli Volcano, satellite passes were available on an average of $\sim 5$ images per day, during the time windows for which ground data has been collected (prior to any data clipping). This number is adequate for the use of our applied monitoring method, though there would be no negative side effects at volcanoes with more frequent passes.

\subsubsection{Recorded history of volcano}

One final piece that is not necessarily required, but can help to expand a time series, is a well documented history of the activity at a volcano. A written record of prior activity can assist to fill in a time series and give relative timeframes for heightened activity. The database at UAF/GINA only contains satellite data as far back as 1993 for the North Pacific and no further back than 2002 for Stromboli. Fortunately, Stromboli has been a heavily studied and documented volcano. Its activity has been recorded as far back as 6000 B.C. using magnetism and radiocarbon data, and 350 B.C. via historical records (Barberi et al., 1993).

\subsubsection{Ground based monitoring systems}

At Stromboli Volcano, the wealth of ground based monitoring equipment serves to fill in, verify, and correct much of the data calculated from the satellite statistical method. For this location, the data makes the monitoring system more reliable as well as serving as a methodology check. For most volcanoes on earth, this abundance of data is not normal, reasonable, or even possible. Short term field campaigns may offer a solution and serve to calibrate and validate satellite data.

\subsection{Potential for future work}

This method has been developed at a very well known and monitored volcano in order to test its feasibility for use at less monitored volcanoes. There are numerous volcanoes around the world that exhibit small explosive activity, and many of these volcanoes are also not suited for ground-based monitoring system deployment. A large number of these volcanoes are located in the North Pacific area, and that is the region that has been chosen for future work and refinement of this method.

\section{Conclusion}

By using a volcano that is heavily monitored and with a comprehensive recorded history a tool for monitoring the frequency of explosive activity has been created in an effort to gain indications to a change in volcanic activity and possible larger eruptions. Using a singular source (space-borne infrared imagery), a time series of eruptive activity for Stromboli was created. This time series is complementary to, and in some cases is able to simulate or duplicate, information gathered from a variety of ground based systems. The frequency of small scale explosions at Stromboli show an increase in number of explosions prior to a cessation of activity which then leads to a large, ash producing 
paroxysmal eruption. These results highlight the capability of satellite remote sensing to become a single source monitoring tool.

The method described here could be useful in an operational setting. It can be especially useful when applied to remote volcanoes that have the potential to impact populations, infrastructure, and the aviation community. Important factors that will affect the validity of application of this method are the availability of a continuous and continually populated dataset, appropriate sensor resolutions, a recorded history of the volcanoes previous activity, and, if available, some groundbased monitoring system (seismic, infrasound, thermal camera, webcam, etc.). This method can be first applied using a database of past images and then be continually updated to help track changes in the volcanic setting and any fluctuations in the level of volcanic (thermal) activity.

\section{Acknowledgments}

I would like to thank Andrew Harris for his help both in the field at Stromboli and throughout the writing process. Special thanks to Peter Webley (UAF/GI) for his tireless help throughout the writing and editing process. Also, the help of those working in the Department of Earth Sciences at University of Firenze (Georgio, Dario). Thanks are also due to those working at Stromboli Volcano, both guiding people to the top (Mario and $\mathrm{ZaZa}$ ) and monitoring the volcano at the COA (Advanced Operations Center).

This project is based on work supported by the United States Geological Survey through the Alaska Volcano Observatory; a NASA Urgent Request Protocal grant for targeting ASTER acquisitions; National Science Foundation (NSF) Interdisciplinary/Collaborative Research under grant no. CMMI-1131799.

\section{References}

Abrams, M., Hook, S., Ramachandran, B., 2002. ASTER User Handbook, Version 2. Jet Propulsion Laboratory, EROS Data Center.

Aguilera, F., 2005. Contrasting styles of volcanic activity as observed by remote sensing: the case of Lascar, Llaima and Villarrica volcanoes, Chile. 6th Int. Symposium on Andean Geodynamics, pp. 21-25 (Ext. Abstract).

Alaska Volcano Observatory (AVO) Website, 2013. http://www.avo.alaska.edu/volcanoes/ volcinfo.php?volcname $=$ Cleveland.

Andronico, D., Branca, S., Calvari, S., Burton, M., Caltabiano, T., Corsaro, R.A., Del Carlo, P., Garfi, G., Lodato, L., Miraglia, L., Murè, F., Neri, M., Pecora, E., Pompilio, M., Salerno, G. Spampinato, L., 2005. A multi-disciplinary study of the 2002-03 Etna eruption: insights into a complex plumbing system. Bull. Volcanol. 27, 314-330.

Barberi, F., Rosi, M., Sodi, A., 1993. Volcanic hazard assessment at Stromboli based on review of historical data. P. Manetti \& J. Keller (Ed.). Acta Vulcanol. 3, 173-187.

Bertagnini, A., Di Roberto, A., Pompilio, M., 2011. Paroxysmal activity at Stromboli: lessons from the past. Bull. Volcanol. 73, 1229-1243.

Bertolaso, G., De Bernardinis, B., Bosi, V., Cardaci, C., Ciolli, S., Colozza, R., Cristiani, C., Mangione, D., Ricciardi, A., Rosi, M., Scalzo, A., Soddu, P., 2009. Civil protection preparedness and response to the 2007 eruptive crisis of Stromboli volcano, Italy. J. Volcanol. Geotherm. Res. 182, 269-277.

Blackburn, E.A.,Wilson, L., Sparks, R.S.J., 1976. Mechanisms and dynamics of strombolian activity. J. Geol. Soc. 132, 429-440.

Calvari, S., Spampinato, L., Lodato, L., Harris, A.J.L., Patrick, M.R., Dehn, J., Burton, M.R., Andronico, D., 2005. Chronology and complex volcanic processes during the 2002-2003 flank eruption at Stromboli volcano (Italy) reconstructed from direct observations and surveys with a handheld thermal camera. J. Geophys. Res. 110, B02201.

Calvari, S.,Spampinato, L., Lodato, L., 2006. The 5 April 2003 vulcanian paroxysmal explosion at Stromboli volcano (Italy) from field observations and thermal data. J. Volcanol. Geotherm. Res. 149 (1-2), 160-175.

Chouet, B., Hamisevicz, N., McGetchin, R., 1974. Photoballistics of volcanic jet activity at Stromboli, Italy. J. Geophys. Res. 79 (32), 4961-4976.

Corradini, S., Spinetti, C., Carboni, E., Tirelli, C., Buongiorno, M.F., Pugnaghi, S., Gangale, G., 2008. Mt. Etna tropospheric ash retrieval and sensitivity analysis using Moderate Resolution Imaging Spectroradiometer measurements. J. Atmos. Remote Sens. 2 , 023550 .

Dean, K.G., Dehn, J., Engle, K., Izbekov, P., Papp, K., Patrick, M., 2002. Operational satellite monitoring of volcanoes at the Alaska Volcano Observatory. Monitoring volcanic hotspots using thermal remote sensing. In: Harris, A.J.H., Wooster, M., Rothery, D.A. (Eds.), Advances in Environmental Monitoring and Modelling, 1, pp. 70-97.

Dehn, J., Harris, A.J.L., 2014. Thermal anomalies at volcanoes in satellite imagery. In: Dean, Dehn (Ed.), Atlas of Volcanic Eruptions from Space. Springer Verlag, New York (in press).
Dehn, J., Dean, K., Engle, K., 2000. Thermal monitoring of North Pacific volcanoes from space. Geology 28 (8), 755-758.

Diller, K., Clarke, A.B., Voight, B., Neri, A., 2006. Mechanisms and conduit plug formation: implications for vulcanian explosions. Geophys. Res. Lett. 33, L20302.

Dozier, J., 1981. A method for satellite identification of surface temperature fields in subpixel resolution. Remote Sens. Environ. 11, 221-229.

Duda, K.A., Ramsey, M.,Wessels, R., Dehn, J., 2009. Optical Satellite Volcano Monitoring: A Multi-Sensor Rapid Response System, Geoscience and Remote Sensing. In: Peter Ho, Pei-Gee (Ed.), ISBN: 978-953-307-003-2. InTech, DOI: http://dx.doi.org/10.5772/ 8303. Available from: http://www.intechopen.com/books/geoscience-and-remotesensing/optical-satellite-volcano-monitoring-a-multi-sensor-rapid-response-system.

Ferrari, L., Manetti, P., 1993. Geodynamic framework of the Tyrrhenian volcanism: a review. In: Manetti, P., Keller, J. (Eds.), Acta Vulcanologica, 3, pp. 1-9.

Francalanci, L., 1993. Mineral chemistry of Stromboli volcanic as indicator of magmatic processes. In: Manetti, P., Keller, J. (Eds.), Acta Vulcanologica, 3, pp. 99-113.

Global Volcanism Network (GVN), 1988. Incandescent tephra from several vents. Sci. Event Alert Netw. (13:11).

Global Volcanism Network (GVN), 1989. Explosions eject bombs and spatter. Sci. Event Alert Netw. 14, 09.

Global Volcanism Network (GVN), 1990. Continued Strombolian activity; new vents. Bull. Glob. Volcanism 15, 09

Global Volcanism Network (GVN), 1991a. Explosive activity from a single crater; strong seismicity. Bull. Glob. Volcanism 16, 04.

Global Volcanism Network (GVN), 1991b. More frequent explosions. Bull. Glob.Volcanism $16,05$.

Global Volcanism Network (GVN), 1993. Explosive activity increases; detailed description of crater. Bull. Glob. Volcanism 18, 04.

Global Volcanism Network (GVN), 1994. Normal Strombolian activity. Bull. Glob. Volcanism 19, 03.

Global Volcanism Network (GVN), 1997. New map of crater terrace. Bull. Glob.Volcanism 22, 05.

Global Volcanism Network (GVN), 2000. Low-to-moderate eruptive activity JanuarySeptember 2000. Bull. Glob. Volcanism 25, 08.

Global Volcanism Network (GVN), 2003. Lava emissions continue into January; crater morphology changes. Bull. Glob. Volcanism 28, 01.

Global Volcanism Network (GVN), 2007. INSIVUMEH reported that during 4-5 January, Strombolian eruptions from Pacaya produced incandescent material that was expelled at 2-40-second intervals, up to $100 \mathrm{~m}$ above the crater. Gas clouds reached an altitude of $2.7 \mathrm{~km}(8,900 \mathrm{ft})$ a.s.l. and drifted S. A lava flow $50 \mathrm{~m}$ in length pooled near the NE edge of MacKenney Cone. Instituto Nacional de Sismologia, Vulcanologia, Meteorologia, e Hidrologia (INSIVUMEH) (3 January, 2007).

Harris, A., Ripepe, M., 2007. Synergy of multiple geophysical approaches to unravel explosive eruption conduit and source dynamics-a case study from Stromboli. Chem. Erde 67, 1-35.

Harris, A.J.L.,Stevenson, D.S., 1997. Thermal observations of degassing open conduits and fumaroles at Stromboli and Vulcano using remotely sensed data. J. Volcanol. Geotherm. Res. 76, 175-198.

Harris, A.J.,Flynn, L.P.,Dean, K.,Pilger, E.,Wooster, M.,Okubo, C.,Wright, R., 2000. Real-time satellite monitoring of volcanic hot spots. Geophys. Monogr. Ser. 116, 139-159.

Harris, A., Dehn, J., Patrick, M., Calvari, S., Ripepe, M., Lodato, L., 2005. Lava effusion rates from hand-held thermal infrared imagery: an example from the June 2003 effusive activity at Stromboli. Bull. Volcanol. 68, 107-117.

Harris, A., Ripepe, M.,Calvari, S.,Lodato, L.,Spampinato, L., 2008. The 5 April 2003 explosion of Stromboli: timing of eruption dynamics using thermal data. The Stromboli Volcano: an integrated study of the 2002-2003 eruption. Geophys. Monogr. Ser. 182, 305-316.

Harris, A.J., Delle Donne, D.,Dehn, J., Ripepe, M.,Worden, A.K., 2013. Volcanic plume and bomb field masses from thermal infrared camera imagery. Earth Planet. Sci. Lett. 365, 77-85.

Hornig-Kjarsgaard, I., Keller, J., Koberski, U.,Stadlbauer, E., Francalanci, L., Lenhart, R., 1993. Geology, stratigrapgy and volcanological evolution of the island of Stromboli, Aeolian arc, Italy. In: Manetti, P., Keller, J. (Eds.), Acta Vulcanologica, 3, pp. 21-68.

Judd, J.W., 1881. Volcanoes. In: Kegan, et al. (Eds.), What They Are and What They Teach D. Appleton and Co, New York, London.

Kreith, F.,Bohn, M.S., 1993. Principles of Heat Transfer, 5th ed. West Publishing Company, St. Paul, Minnesota.

Lacroix, A., 1904. Montagne Pelée et ses Éruptions. Masson et Cie Éditeurs, Paris, pp. 1-662.

Lillesand, T.M.,Keifer, R.W.,Chipman, J.W., 2008. Remote Sensing and Image Interpretation, 6 th ed. John Wiley \& Sons, Inc., Hoboken, New Jersey.

LP DAAC ASTER Overview, 2013. Last visited https://lpdaac.usgs.gov/products/aster overview.

LP DAAC MODIS Overview, 2013. Last visited https://pdaac.usgs.gov/products/modis overview.

Macdonald, G.A., 1972. Volcanoes. Prentice-Hall inc, Englewood Cliffs, New Jersey (510 pp.).

Marchetti, E., Ripepe, M., 2005. Stability of the seismic source during effusive and explosive activity at Stromboli Volcano. Geophys. Res. Lett. 32, L03307.

MODIS Rapid Response, d. last visited 2013 http://earthdata.nasa.gov/data/near-realtime-data/rapid-response.

NASA MODIS Web, 2013. Technical specifications, last viewed. http://modis.gsfc.nasa.gov.

NASA/JPL/ASTER User Advisory, 2009. Change in status alert, January 12, 2009. http:// asterweb.jpl.nasa.gov/latest.asp.

Neuberg, J., Luckett, R., Ripepe, M., Braun, T., 1994. Highlights from a seismic broadband array on Stromboli volcano. Geophys. Res. Lett. 21 (9), 749-752.

Neuberg, J., Luckett, R., 1996. Seismo-volcanic sources on Stromboli volcano. Ann. Geofis. XXXIX, 377-391. 
NOAA, C.L.A.S.S., 2013. website-last visited http://www.class.ncdc.noaa.gov/saa/ products/welcome.

Patrick, M.R., 2002. Numerical modeling of lava flow cooling applied to the 1997 Okmok Eruption: comparison with AVHRR thermal imagery. University of Alaska Fairbanks, Fairbanks (M.S. thesis, 141 pp.).

Patrick, M.R., Dehn, J., Dean, K., 2005. Numerical modeling of lava flow cooling applied to the 1997 Okmok eruption: comparison with advanced very high resolution radiometer thermal imagery. J. Geophys. Res. 110, B02210.

Patrick, M., Harris, A., Ripepe, M., Dehn, J., Rothery, D., Calvari, S., 2007. Strombolian explosive styles and source conditions: insights from thermal (FLIR) video. Bull. Volcanol. 69, 769-784.

Pioli, L., Erlund, E., Johnson, E., Cashman, K., Wallace, P., Rosi, M., Delgado Granados, H., 2008. Explosive dynamics of violent Strombolian eruptions: the eruption of Parícutin Volcano 1943-1952 (Mexico). Earth Planet. Sci. Lett. 271, 359-368.

Prata, A.J., 1989a. Infrared radiative transfer calculations for volcanic ash clouds. Geophys. Res. Lett. 16 (11), 1293-1296.

Prata, A.J., 1989b. Observations of volcanic ash clouds in the $10-12 \mu \mathrm{m}$ window using AVHRR/2 data. Int. J. Remote Sens. 10 (4-5), 751-761.

Ripepe, M.,Harris, A.J.L., 2008. Dynamics of the 5 April 2003 explosive paroxysm observed at Stromboli by a near-vent thermal, seismic, and infrasonic array. Geophys. Res. Lett. 35, 7. http://dx.doi.org/10.1029/2007GL032533.

Ripepe, M., Marchetti, E., Ulivieri, G., 2007. Infrasonic monitoring at Stromboli volcano during the 2003 effusive eruption: insights on the explosive and degassing process in an open conduit system. J. Geophys. Res. 112, 1-13 (BO9207).
Ripepe, M., Delle Donne, D., Harris, A., Marchetti, E., Ulivieri, G., 2008. Dynamics of Strombolian activity. The Stromboli Volcano: an integrated study of the 2002-2003 eruption. Geophys. Monogr. Ser. 182, 39-48.

Rosi, M.,Bertagnini, A.,Landi, P., 2000. Onset of the persistent activity at Stromboli Volcano (Italy). Bull. Volcanol. 62, 294-300

Rosi, M., Bertagnini, A.,Harris, A.J.L.,Pioli, L.,Pistolesi, M., Ripepe, M., 2006. A case history of paroxysmal explosions at Stromboli: timing and dynamics of the April 5, 2003 event. Earth Planet. Sci. Lett. 243 (3-4), 594-606.

Stix, J., Torres, C.R., Narváez, M.L., Cortés, G.P.J., Raigosa, A.J., Gómez, M.D., Castonguay, R., 1997. A model of vulcanian eruptions at Galeras volcano, Colombia. J. Volcanol. Geotherm. Res. 77, 285-303.

Universita di Firenze, Dipartimento di Scienze della Terra (UF), 2011. Activity Bulletin. http://193.206.127.20/stromboli/ (January 6).

Walker, G.P.L., 1973. Explosive volcanic eruptions, a new classification scheme. Geol. Rund. 62, 431-446.

Watson, I.M.,Prakash, A., 2014. Satellite systems and interactions. In: Dean \& Dehn (Ed.), Atlas of Volcanic Eruptions from Space. Springer Verlag, New York (in press).

Webley, P.W., Dehn, J., Lovick, J., Dean, K.G., Bailey, J.E., Valcic, L., 2009. Near-real-time volcanic ash cloud detection: experiences from the Alaska Volcano Observatory. J. Volcanol. Geotherm. Res. 186 (1), 79-90.

Wohletz, K., Heiken, G., 1992. Volcanology and Geothermal Energy. University of California Press, Berkeley.

Wright, R., Flynn, L.P., Garbeil, H., Harris, A.J., Pilger, E., 2004. MODVOLC: near-real-time thermal monitoring of global volcanism. J. Volcanol. Geotherm. Res. 135 (1), 29-49. 